\title{
Potencial do latex da fruta pão (Artocarpus altilis) como agente coagulante do leite
}

\author{
Potential of breadfruit (Artocarpus altilis) latex as a milk-clotting agent
}

\begin{abstract}
Elisângela França Soares ${ }^{I}$ Anna Carolina da Silva ${ }^{I}$ Alana Emilia Soares de França Queiroz ${ }^{I}$ José Erick Galindo Gomes ${ }^{I}$ Polyanna Nunes HerculanoII Keila Aparecida Moreira ${ }^{I^{*}}$
\end{abstract}

\section{RESUMO}

A fruta-pão é uma árvore exótica no Brasil, onde se aclimatou muito bem. Embora seja uma planta lactífera, o conhecimento sobre seu látex é escasso. No entanto, sabe-se que enzimas proteolíticas correspondem a mais de $50 \%$ da composição do látex em plantas lactíferas. O objetivo deste estudo foi avaliar o potencial do látex da fruta-pão (Artocarpus altilis var. Apyrena) como fonte de protease coagulante do leite e caracterizar parcialmente a enzima. A atividade proteolítica da fração de extrato bruto foi avaliada utilizando azocaseina e, para a quantificação das proteínas totais, o ácido bicinconínico (BCA). A atividade de coagulação do leite foi testada utilizando leite desnatado a $12 \%$. A protease foi testada em diferentes condições de temperatura (35 a $\left.80^{\circ} \mathrm{C}\right)$ e $\mathrm{pH}(5,8$ a 10,7$)$ e apresentou atividade ótima a $50^{\circ} \mathrm{C}$ e $\mathrm{pH}$ alcalino $(8,5)$ sendo estável a estas variáveis durante 120 minutos. A atividade coagulante no leite foi diretamente proporcional à temperatura na melhor concentração de $\mathrm{CaCl}_{2}$ a $10 \mu \mathrm{mol} \mathrm{L}^{-1}$. Os resultados indicam que a enzima analisada é uma possivel alternativa à quimosina.

Palavras-chave: enzimas coagulantes do leite, atividade proteolítica, coagulante vegetal, fruta-pão.

\section{ABSTRACT}

Breadfruit is an exotic tree in Brazil, very well acclimatized. Despite of being a laticifer plant, the knowledge about its latex is scarce. However, it is known that proteolytic enzymes represents over $50 \%$ of the latex composition in laticifers plants. The aim of this study was to evaluate the potential of breadfruit (Artocarpus altilis var. Apyrena) latex as a source of milk clotting proteases and partially characterize it. The proteolytic activity of the fraction of crude extract was assessed using azocasein and quantitation of total protein, the bicinchoninic acid (BCA). Milkclotting activity was analyzed using skim milk at $12 \%$. The enzyme activity was analyzed under different temperature conditions (35 to $\left.80^{\circ} \mathrm{C}\right)$ and $\mathrm{pH}(5.8$ to 10.7$)$ presenting optimum activity in alkaline $\mathrm{pH}(8.5)$ and $50^{\circ} \mathrm{C}$; being stable to the two variables at 120 minutes during the test. The clotting activity was directly proportional to the temperature at the better concentration of $\mathrm{CaCl}_{2}\left(10 \mathrm{mmol} \mathrm{L} \mathrm{L}^{-1)}\right.$. The results indicate that enzyme is a possible replacement for calf rennet.

Key words: milk-clotting enzyme, proteolytic activity, plant rennet, breadfruit.

\section{INTRODUÇÃO}

A coagulação do leite é uma etapa fundamental na elaboração de alguns tipos de produtos alimentícios, sendo comumente realizada em presença de proteases coagulantes (EGITO \& LAGUNA, 2006). As proteases se destacam em relação às suas aplicações comerciais e sua importância em diferentes processos fisiológicos. Essas proteínas são encontradas na natureza, podendo ser obtidas a partir de animais, vegetais e microorganismos (RAO et al., 1998).

As proteases constituem um dos grupos mais importantes de enzimas industriais, que têm como uma das principais aplicações a produção de queijo da indústria de laticínios, sendo a quimosina uma das mais utilizadas, tradicionalmente extraída do abomaso de bezerros (MERHEB-DINI et al., 2010). Contudo, desde 1961, a oferta desse coagulante de origem animal não mais atende à demanda comercial, frente ao aumento na produção de queijos, aliado ao alto custo desse produto e às considerações

\footnotetext{
IUnidade Acadêmica de Garanhuns (UAG), Universidade Federal Rural de Pernambuco (UFRPE), 55292-270, Garanhuns, PE, Brasil. E-mail: moreirakeila@hotmail.com.*Autor para correspondência.

IIPrograma de Pós-graduação em Biociência Animal (PPGBA), UFRPE, Recife, PE, Brasil.
} 
éticas e religiosas associadas ao seu uso. Esses fatos incentivam a busca por novas alternativas, despertando o interesse crescente por coagulantes vegetais e microbianos (AHMED et al., 2010; JACOB et al., 2011).

Micro-organismos utilizados pela engenharia genética podem fornecer quantidade quase ilimitada de coagulantes apropriados, mas há algumas restrições ao consumo (GRUNERT et al., 2001, LÄHTEENMÄKI et al., 2002), como as normas legais em vários países europeus, que proíbem a participação de organismos geneticamente modificados na fabricação de queijos orgânicos (EC, 2007). Dentre as proteases de origem vegetal oriundas de látex utilizadas na indústria, estão a papaína, extraída de Carica papaya, e a ficina, de Ficus glabra (ALAIS, 1985). Estudos foram realizados utilizando proteases coagulantes no leite, provenientes de plantas da região do semi-árido brasileiro, a fim de se determinar sua aplicação na produção de queijos, como as proteases do látex de Jacaratia corumbensis O. Kuntze (DUARTE et al., 2009) e Sideroxylon obtusifolium (SILVA et al., 2013). É provável que outras plantas lactíferas nativas ou exóticas do Nordeste brasileiro, também possam ser empregadas na indústria de alimentos.

A fruta-pão (Artocarpus altilis ) é originária da região do Pacífico ocidental. De adaptação versátil, está atualmente espalhada por todas as regiões tropicais e subtropicais do mundo. As variedades conhecidas são a apyrena, sem sementes ou "fruta-pão de massa", e seminífera, com sementes, "fruta-pão de caroço" (RAGONE, 1997, ZEREGA et al., 2004).

$\mathrm{O}$ interesse científico em proteases e suas ações em diferentes proteínas dos alimentos pode resultar em melhores produtos, além de também estimular o desenvolvimento de novas aplicações (MERHEB, 2007). Diante do exposto e da constatação dos reduzidos estudos científicos, tornam-se relevantes novas pesquisas, que viabilizem a produção de coalhos vegetais. Portanto, o objetivo deste trabalho foi avaliar a atividade proteolítica e coagulante de enzimas obtidas a partir do látex da fruta-pão.

\section{MATERIAL E MÉTODOS}

O extrato enzimático foi extraído da planta fruta-pão (Artocarpus altilis) através da coleta de seu látex, que ocorreu no município de Recife - PE. O látex foi obtido pela retirada dos frutos (estado maturo) de seus respectivos caules, culminando no seu gotejamento e armazenamento em microtubos. Posteriormente foi solubilizado em solução tampão fosfato $0,1 \mathrm{M}, \mathrm{pH} 7,0$, na proporção de $1 \mathrm{~g}$ de látex para $10 \mathrm{~mL}$ de solução, sendo transportado para o
Centro Laboratorial de Apoio à Pesquisa da Unidade Acadêmica de Garanhuns (CENLAG-UAG/UFRPE) sob refrigeração $\left(4^{\circ} \mathrm{C}\right.$, em caixa isotérmica). Essa mistura foi mantida sob agitação por uma hora para acelerar a solubilização, seguida da filtração em papel filtro e congelada a $-20^{\circ} \mathrm{C}$ para posterior análise.

A concentração proteica do extrato solúvel foi determinada pelo método do ácido bicinconínico (kit BCA Protein Assay, Thermo Fisher Pierce, EUA). A absorbância dos ensaios foi de $562 \mathrm{~nm}$ e com limitação de detecção a $0,5 \mathrm{mg} \mathrm{L}^{-1}$, utilizando solução padrão de soro albumina bovina (BSA) para plotagem da curva de calibração.

A capacidade coagulante do látex da fruta-pão no leite foi analisada conforme o método de ARIMA et al. (1970), utilizando 1,0mL de solução de leite em pó desnatado a $12 \%$ (p/v) como substrato, contendo $10 \mu \mathrm{M}$ de $\mathrm{CaCl}_{2}$, pré-aquecida por 10 minutos em banho-maria a $37^{\circ} \mathrm{C}$, seguida da adição de $100 \mu \mathrm{L}$ do extrato enzimático. Uma unidade coagulante no leite por mililitro $\left(\mathrm{U} \mathrm{mL}^{-1}\right)$ foi expressa pela fórmula $400 \mathrm{t}^{-1}$, sendo a quantidade de enzima que coagula o leite em 1 minuto definida por conter 400 unidades, e t o tempo necessário para a formação dos primeiros grumos de coagulação no leite.

A atividade proteolítica foi determinada segundo o método de ALENCAR et al. (2003), utilizando $100 \mu \mathrm{L}$ de azocaseína (1,0\% p/v em tampão Tris-HCl, 0,2M epH 7,2) e $60 \mu \mathrm{L}$ do extrato enzimático. A mistura reacional foi incubada durante uma hora, à temperatura ambiente e posteriormente interrompida pela adição de $480 \mu \mathrm{L}$ de ácido tricloroacético (TCA) a $10 \%(\mathrm{p} / \mathrm{v})$, sendo centrifugada por 20 minutos a $1000 \times g$ e temperatura de $4^{\circ} \mathrm{C}$. Após a centrifugação, foi retirado $320 \mu \mathrm{L}$ do sobrenadante, adicionando-o a $560 \mu \mathrm{L}$ de hidróxido de sódio (1M). Uma unidade de atividade proteolítica (U) foi definida como a variação de 0,01 na absorbância a 440nm durante uma hora.

$\mathrm{O}$ pH ótimo para atividade enzimática da protease foi determinado utilizando-se os tampões: fosfato $0,1 \mathrm{M}(\mathrm{pH} 5,8 ; 6,0 ; 7,0 ; 8,0$ e 9,0); Tris$\mathrm{HCl} 0,1 \mathrm{M}(\mathrm{pH} 7,0 ; 7,5 ; 8,0 ; 8,5$ e 9,0$)$ e carbonatobicarbonato $0,1 \mathrm{M}(\mathrm{pH} 8,5 ; 9,2 ; 10,0 ; 10,7$ e 11,9$)$ a $37^{\circ} \mathrm{C}$. Para a determinação da temperatura ótima, foram realizadas as atividades de coagulação do leite e proteásica em diferentes temperaturas: $35,40,45$, $50,55,60,70$, e $80^{\circ} \mathrm{C}$ e $35,45,50,55,60,70$, e $80^{\circ} \mathrm{C}$, respectivamente, em $\mathrm{pH}$ ótimo do extrato enzimático.

A estabilidade ao $\mathrm{pH}$ do extrato foi realizada diante de valores de $\mathrm{pH}$ combinados com as soluções tampão: fosfato $0,1 \mathrm{M}(\mathrm{pH} 5,8 ; 6,0$; 7,$0 ; 8,0$ e 9,0); Tris- $\mathrm{HCl} 0,1 \mathrm{M}(\mathrm{pH} \mathrm{7,0;7,5;8,0;}$ $8,5$ e 9,0$)$ e carbonato-bicarbonato $0,1 \mathrm{M}(\mathrm{pH} 8,5$; $9,2 ; 10,0 ; 10,7$ e 11,9$)$, em sua temperatura ótima, retirando alíquotas para a determinação da atividade 
proteásica, nos intervalos de tempo de $0,60,120$ e 180 minutos. Para a determinação da estabilidade à temperatura, a enzima foi previamente submetida às temperaturas de $35,45,50,55,60,70$ e $80^{\circ} \mathrm{C}$, em seu pH ótimo, sendo retiradas alíquotas para a determinação da atividade proteásica nos seguintes intervalos de tempo de 0, 60, 120 e 180 minutos.

$\mathrm{O}$ efeito da concentração de $\mathrm{Ca}^{2+}$ na coagulação do leite foi avaliado segundo metodologia de ARIMA et al. (1970), porém com diferentes concentrações de $\mathrm{CaCl}_{2}(1,5,10$ e $15 \mu \mathrm{M})$. Todos os experimentos foram realizados em triplicata e os resultadossãoexpressosemmédia \pm desviopadrão(DP).

\section{RESULTADOS E DISCUSSÃO}

O extrato bruto do látex da fruta-pão apresentou atividades proteásica e coagulante satisfatórias. Quando submetida ao teste de coagulação, a enzima coagulou o leite em 1 minuto e 48 segundos a $37^{\circ} \mathrm{C}$ e quase que instantaneamente a temperatura de $80^{\circ} \mathrm{C}$, sendo a razão atividade coagulante/atividade proteásica (8272) suficientemente alta, sugerindo a possibilidade de produção comercial de queijos. Este dado revela que a enzima presente no látex tem especificidade para hidrolisar a $\kappa$-caseína, devido à ausência de hidrólise excessiva de outras proteínas, que não estão relacionadas com a coagulação do leite $\mathrm{e}$ que poderiam diminuir o rendimento e a qualidade do produto (NEVES-SOUZA \& SILVA, 2005; JAROS et al., 2008).

Quanto ao $\mathrm{pH}$, a protease do extrato bruto do látex da fruta-pão obteve melhor resultado experimental em pH 8,5 para o tampão Tris-HCl(Figura 1), não sendo o mesmo observado para o tampão carbonato-bicarbonato no mesmo pH. É possível que a atividade da enzima tenha sido modificada pela presença de algum ligante (íons) no tampão agindo como co-fator, alterando a conformação da enzima. No entanto, os dados referentes ao $\mathrm{pH}$ corroboram os encontrados por SILVA et al. (2013) e TRIPATHI et al. (2011), que, ao estudarem proteases do látex de Sideroxylon obtusifolium e Streblus asper, respectivamente, encontraram maior atividade proteásica em $\mathrm{pH} 8,0$, para a primeira, e $\mathrm{pH}$ 9,0 , para a segunda. O extrato apresentou seus melhores resultados com atividade proteásica relativa acima de $50 \%$ em uma faixa de $\mathrm{pH}$ entre 7,5 e 10,0, sugerindo que essa enzima pertença ao grupo de proteases alcalinas, um dos grupos mais utilizados comercialmente (KRIK et al., 2002). Resultados similares foram vistos por TOMAR et al. (2008) com látex de Wrightia tinctoria (Roxb.) R. Br., que observaram atividade ótima no intervalo de $\mathrm{pH}$ de 7,5 a 10.

A maior atividade de coagulação foi apresentada na concentração de $\mathrm{CaCl}_{2}(10 \mu \mathrm{mol})$, em que se comportou diretamente proporcional à temperatura, chegando a $100 \%$ de atividade residual na temperatura de $80^{\circ} \mathrm{C}$. Segundo CHAZARRA et al. (2007), ao estudaremainfluência datemperatura sobrea atividade coagulação do leite de extratos de flores secas da alcachofra, observaram, na faixa de temperatura de $20-60^{\circ} \mathrm{C}$, que o tempo de coagulação também diminuía à medida que a temperatura era elevada. O melhor resultado experimental da temperatura para a atividade proteásica da amostra foi de $50^{\circ} \mathrm{C}$ (Figura 2), apresentando atividade relativa

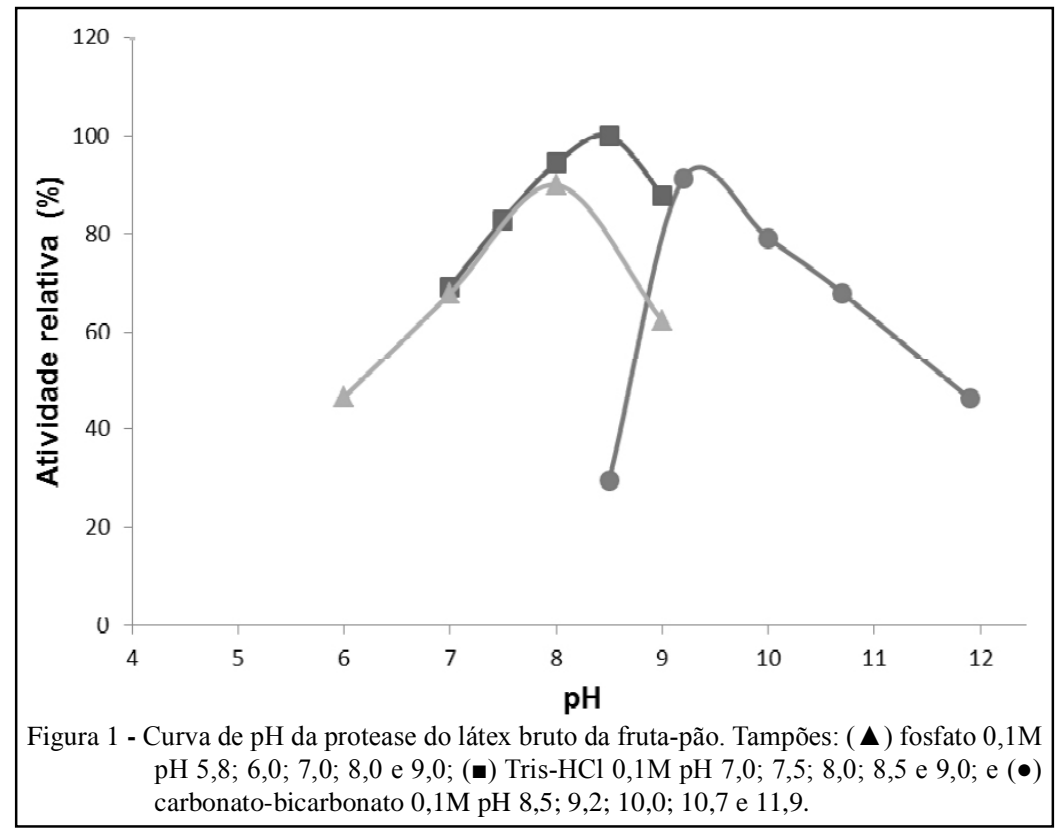

Ciência Rural, v.45, n.1, jan, 2015. 


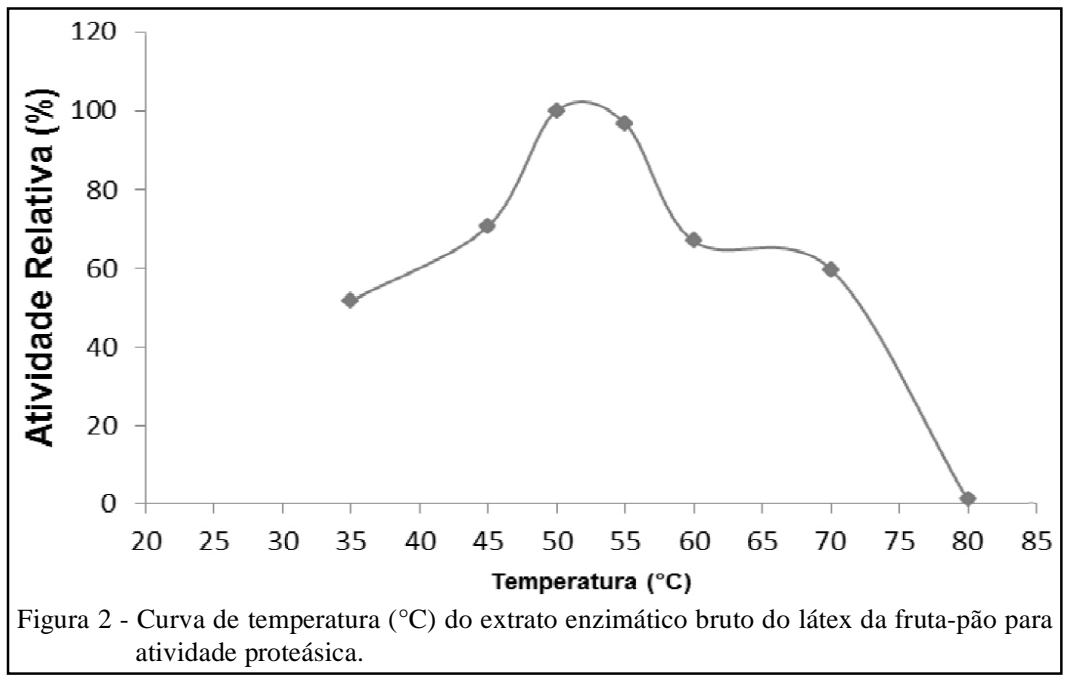

acima de $50 \%$ para a maioria das temperaturas testadas, com exceção da temperatura de $80^{\circ} \mathrm{C}$. Esse resultado corrobora os apresentados por DUARTE et al. (2009), que trabalharam com a protease do látex de Jacaratia corumbensis O. Kuntze, por SILVA et al. (2013), que trabalharam com a protease do látex da Sideroxylon obtusifolium, e obtiveram melhor atividade proteásica aos $55^{\circ} \mathrm{C}$. DUBEY \& JAGANNADHAM (2003) realizaram estudo em protease extraída da Calotropis procera, com atividade ótima entre 55 e $60^{\circ} \mathrm{C}$.

A enzima foi estável na faixa de $\mathrm{pH}$ 5,810,7 (Figura 3). Apesar do declínio observado na curva de estabilidade da enzima, esta apresentou atividade residual em todas as faixas de $\mathrm{pH}$, sendo o resultado mínimo apresentado de $19 \%$ aos 180 minutos do ensaio para o $\mathrm{pH}$ 7,0 em tampão fosfato, e máximo de $133 \%$ aos 60 minutos do ensaio para o pH 10,7, em tampão carbonato-bicarbonato. Segundo DEMIR et al. (2008), ao estudarem as proteases extraídas de Capparis spinosa, enzimas estáveis ao $\mathrm{pH}$ são vantajosas na produção de alimentos. Ao exemplo da papaína e bromelina, tradicionais proteases vegetais, reportadas com estabilidade entre pH 5,0 a 9,0 (RAO et al., 1998). É importante que os coagulantes não sejam sensíveis a variações do pH do leite, pois sua característica estável evita diminuição do rendimento do queijo, como também a formação de queijos defeituosos originados de um coágulo flácido ao corte (HARBOE \& BUDTZ, 1999).

Quanto à estabilidade à temperatura, a atividade proteásica residual do extrato (Figura 4) manteve-se acima de $40 \%$ para todos os tempos e

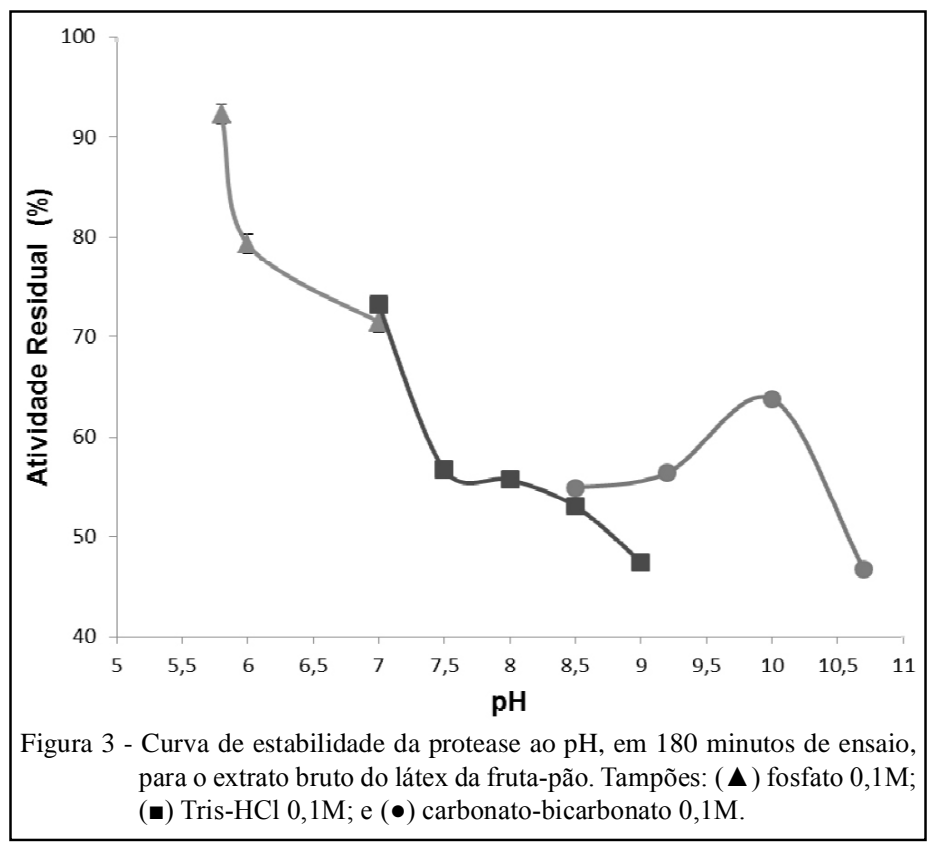

Ciência Rural, v.45, n.1, jan, 2015. 


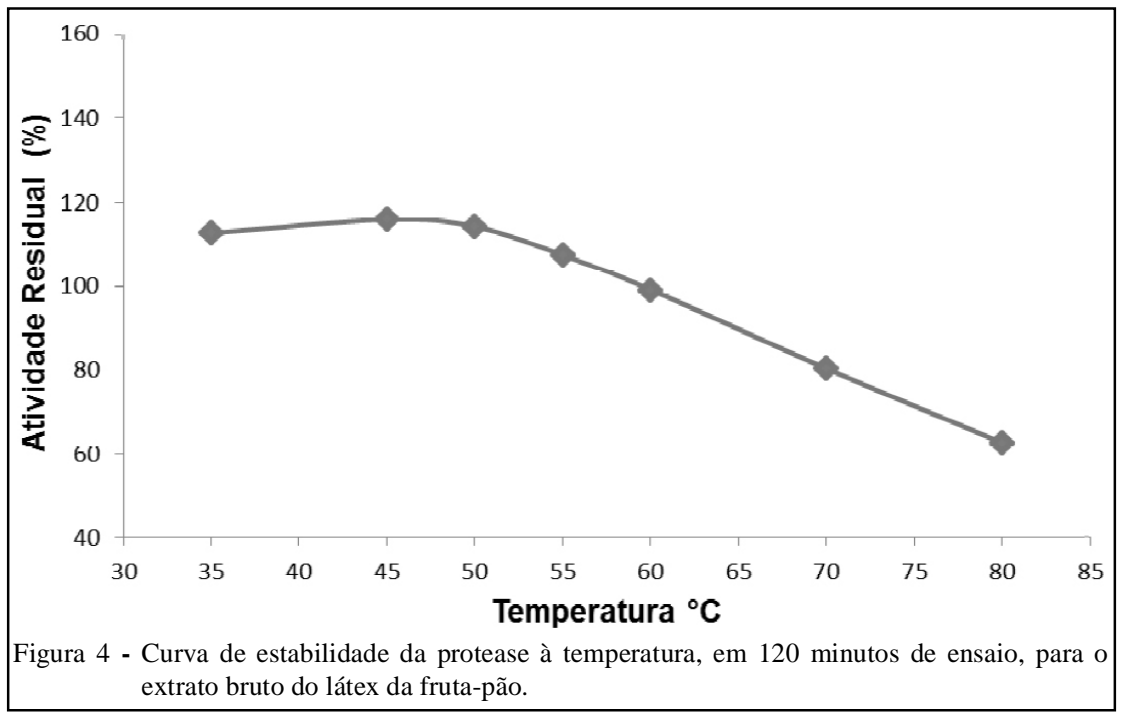

temperaturas analisados, atingindo seu valor máximo a $70^{\circ} \mathrm{C}$ aos 180 minutos $\left(141 \mathrm{U} \mathrm{mg}^{-1}\right)$. O extrato apresentou redução da atividade à medida que a temperatura atingiu $80^{\circ} \mathrm{C}$ para as temperaturas de 35 a $60^{\circ} \mathrm{C}$, devido à desnaturação térmica da proteína, mostrando que a enzima perde atividade quando exposta às temperaturas mais elevadas. Esse resultado corrobora o trabalho de DUARTE et al. (2009) com a protease de Jacaratia corumbensis O. Kuntze. O extrato analisado manteve atividade residual superior a $80 \%$ na faixa de temperatura de 35 a $70^{\circ} \mathrm{C}$.

\section{CONCLUSÃO}

O látex bruto da fruta-pão é uma fonte potencial de proteases coagulantes do leite. O desempenho mais satisfatório para a atividade coagulante no leite foi em $\mathrm{pH}$ alcalinoe em temperatura superior a $40^{\circ} \mathrm{C}$, sendo estável à temperatura e ao $\mathrm{pH}$. Os resultados obtidos demonstraram que o látex da fruta-pão é uma possível alternativa ao coalho animal, abrindo espaço para estudos futuros, a fim de verificar o seu potencial de aplicações em alimentos.

\section{REFERÊNCIAS}

AHMED, I.A.M et al. $\mathrm{pH}$ stability and influence of salts on activity of a milk-clotting enzyme from Solanum dubium seeds and its enzymatic action on bovine caseins. Food Science and Technology, v.43, p.1-6, 2010. Disponível em: <http://dx.doi. org/10.1016/j.lwt.2009.12.011>. Acesso em: 03 jun. 2013. doi: 10.1016/j.lwt.2009.12.011.

ALAIS, C. Ciencia de la leche. Barcelona: Reverte, 1985. 873p.

ALENCAR, R.B. et al. Alkaline proteases from the digestive tract of four tropical fishes. Brazilian Journal of Food Technology. v.6, n. 2, p.279-284, 2003.
Disponível em: <http://www.ital.sp.gov.br/bj/artigos/ brazilianjournal/free/p03142.pdf>. Acesso em: 03 jun. 2013.

ARIMA, K. et al. Milk-clotting enzyme from Mucor pusillus var. Lindt. Methods in Enzymology, v.19, p.446-459, 1970. Disponível em: <http://dx.doi.org/10.1016/0076-6879(70)190331>. Acesso em: 03 jun. 2013. doi: 10.1016/0076-6879(70)19033-1.

CHAZARRA, S. et al. Characterization of the milk-clotting properties of extracts from artichoke (Cynara scolymus, L.) flowers. International Dairy Journal, v.17, p.1393-1400, 2007. Disponível em: <http://dx.doi.org/10.1016/j.idairyj.2007.04.010>. Acesso em: 03 jun. 2013. doi: 10.1016/j.idairyj.2007.04.010.

DEMIR, Y. et al. Cysteine protease (capparin) from capsules of Caper (Capparis spinosa). Food Technology and Biotechnology, v.46, n.3, p.286-291, 2008. Disponível em: <http://go.galegroup.com.ez19.periodicos.capes.gov.br/ps/i.do ?id=GALE \% 7CA $187909344 \& \mathrm{v}=2.1 \& \mathrm{u}=$ capes $58 \& \mathrm{it}=\mathrm{r} \& \mathrm{p}=\mathrm{AO}$ NE\&sw=w>. Acesso em: 03 jun. 2013.

DUARTE, A.R. et al. Jacaratia corumbensis O. Kuntze a new vegetable souece for milk-clotting enzymes. Brasilian Archieves of Biology and Technology, v.52, p.1-9, 2009. Disponível em: <http://dx.doi.org/10.1590/S1516-89132009000100001>. Acesso em: 03 jun. 2013. doi: 10.1590/S1516-89132009000100001.

DUBEY, V.K.; JAGANNADHAM, M.V. Procerain, a stable cysteine protease from the latex of Calotropis procera. Phytochemistry, v.62, p.1057-1071, 2003. Disponível em: <http://dx.doi.org/10.1016/S0031-9422(02)00676-3>. Acesso em: 03 jun. 2013. doi: 10.1016/S0031-9422(02)00676-3.

EC (COUNCILREGULATION). No 834007 on Organic Production and Labelling of Organic Products and Repealing Regulation (EEC) No 2092/91. Brussels: Council of the European Union, 2007.

EGITO, A.S.; LAGUNA, L.E. Produtos regionais derivados de leite de cabras e perspectivas de mercado para o Brasil. In: Reunião Anual da Sociedade Brasileira de Zootecnia, 43., 2006, João Pessoa, PB. p.703-715. Disponível em: <http://ainfo. cnptia.embrapa.br/digital/bitstream/item/35222/1/AAC-Produtosregionais.pdf>. Acesso em: 03 Jun. 2007. 
GRUNERT, K.G. et al. Consumer perceptions of food products involving genetic modification - results from a qualitative study in four Nordic countries. Food Quality and Preference, v.12, p.527-542, 2001. Disponível em: <http://www.sciencedirect.com/ science/article/pii/S0950329301000490>. Acesso em: 12 fev. 2014. doi: 10.1016/S0950-3293(01)00049-0.

HARBOE, M.K.; BUDTZ, P. The production, action and application of rennet and coagulants. Technology of Cheesemaking. Sheffield: Academic, 2010. p.33-65.

JACOB, M. et al. Recent advances in milk clotting enzymes. International Journal of Dairy Technology, v.64, n.1, p.14-33, 2011. Disponível em: <http://onlinelibrary.wiley.com/doi/10.1111/ j.1471-0307.2010.00633.x/abstract>. Acesso em: 03 jun. 2013. doi: 10.1111/j.1471-0307.2010.00633.x.

JAROS, D. et al. Enzymatic coagulation of milk: animal rennets and microbial coagulants differ in their gelation behaviour as affected by $\mathrm{pH}$ and temperature. International Journal of Food Science and Technology, v.43, p.1721-1727, 2008. Disponível em: <http:// www.readcube.com/articles/10.1111/j.1365-2621.2008.01749.x>. Acesso em: 03 jun. 2013. doi: 10.1111/j.1365-2621.2008.01749.x.

KRIK, O. et al. Industrial enzyme applications. Current Opinion in Biotechnology, v.13, p.345-435, 2002. Disponível em: <http:// dx.doi.org/10.1016/S0958-1669(02)00328-2>. Acesso em: 03 jun. 2013. doi:.10.1016/S0958-1669(02)00328-2.

LÄHTEENMÄKI, L. et al. Acceptability of genetically modified cheese presented as real product alternative. Food Quality and Preference, v.13, p.523-533, 2002. Disponível em: <http://www.sciencedirect.com/science/article/pii/ S0950329301000775>. Acesso em: 12 fev. 2014. doi: 10.1016/ S0950-3293(01)00077-5.

LEWINSOHN, T.M. The geographical distribution of plant látex. Chemoecology, v.2, p.64-68, 1991. Disponível em: <http://link. springer.com/article/10.1007\%2FBF01240668>. Acesso em: 03 jun. 2013. doi: 10.1007/BF01240668.

MERHEB, C.W. et al. Partial characterization of protease from a thermophilic fungus, Thermoascus aurantiacus, and its hydrolytic activity on bovine casein. Food Chemistry, v.104, p.127-131, 2007. Disponível em: <http://dx.doi.org/10.1016/j. foodchem.2006.11.010>. Acesso em: 03 jun. 2013. doi: 10.1016/j. foodchem.2006.11.010
MERHEB-DINI, C. et al. Production and characterization of a milk-clotting protease in the crude enzymatic extract from the newly isolated Thermomucor indicae-seudaticae N31 (Milk-clotting protease from the newly isolated Thermomucor indicae-seudaticae N31). Food Chemistry, v.120, p.87-93, 2010. Disponível em: <http://dx.doi.org/10.1016/j.foodchem.2009.09.075>. Acesso em: 03 jun. 2013. doi: 10.1016/j.foodchem.2009.09.075.

NEVES-SOUZA, R.D.; SILVA, R.S.S.F. Study of cost and yield of minas like fresh cheese produced with added fat free soybean hydro-soluble extract powder with curd formed by different coagulants agents. Food Science and Technology, v.25, n.1, p.170-174, 2005. Disponível em: <http://dx.doi.org/10.1590/ S0101-20612005000100028>. Acesso em: 03 jun. 2013. doi: 10.1590/S0101-20612005000100028.

RAGONE, D. Breadfruit,Artocarpusaltilis (Parkinson) Fosberg. Rome: International Plant Genetic Resources Institute, 1997. 77p.

RAO, M.B. et al. Molecular and biotechnological aspects of microbial proteases. Microbiology and Molecular Biology Reviews, v.62, p.597-635, 1998. Disponível em: <http://mmbr.asm. org/content/62/3/597.full.pdf+html>. Acesso em: 03 jun. 2013.

SILVA, A.C. et al. Potential of quixaba (Sideroxylon obtusifolium) latex as a milk-clotting agent. Food Science and Technology, v.33, p.494-499, 2013. Disponível em: <http://www.scielo.br/ scielo.php?pid=S0101-20612013000300017\&script=sci_arttext $>$. Acessoem: 12 fev. 2014. doi: 10.1590/S0101-20612013005000075.

TOMAR, R. et al. A stable serine protease, Wrightin, from the látex os the plant Wrightia tinctoria (Roxb.) $\mathrm{R}$. Br.: purificacion and biochemical properties. Journal of agricultural and food chemistry, v.56, p.1479-1487, 2008. Disponível em: <http://pubs. acs.org/doi/abs/10.1021/jf0726536>. Acesso em: 03 jun. 2013. doi: $10.1021 /$ jf0726536.

TRIPATHI, P. et al. Purification and biochemical characterisation of a novel protease streblin. Food Chemistry, v.125, p.10051012, 2011. Disponível em: <http://dx.doi.org/10.1016/j. foodchem.2010.09.108>. Acesso em: 03 jun. 2013. doi: 10.1016/j. foodchem.2010.09.108.

ZEREGA, N.J.C. et al. Complex origins of breadfruit (Artocarpus altilis, Moraceae): implications for human migrations in Oceania. American Journal of Botany, v.91, p.760-766, 2004. Disponível em: <http://www.amjbot.org/content/91/5/760>. Acesso em: 03 jun. 2013. doi: 10.3732/ajb.91.5.760. 